\title{
A new method for storage of block samples: a pilot study
}

\author{
H. A. AMUNDSEN* A. EMDAL $\uparrow$ and V. THAKUR $\dagger$
}

\begin{abstract}
A new method for storing mini-block samples was developed by the Norwegian University of Science and Technology. The method consists of storing samples inside a pressurised storage cell (PSC) in order to minimise the effects of stress relief. The pilot study consists of nine mini-block samples that were stored and tested at the sampling site. The samples were sealed with a rubber membrane and storage cell at the site, shortly after sampling. Thereafter, an isotropic pressure was applied and maintained constant throughout the storage period of up to 2 months while the excess water was monitored. The results indicate that the storage method reduces $/$ minimises the effects of stress relief and ageing during the time delay between sampling and testing. The conducted tests indicate that samples stored inside the PSC result in geotechnical parameters that are close to the $0 \mathrm{~d}$ samples, which were tested less than an hour after the sampling.
\end{abstract}

\section{KEYWORDS: clays; laboratory equipment; sampling}

Published with permission by the ICE under the CC-BY 4.0 license. (http://creativecommons.org/licenses/by/4.0/)

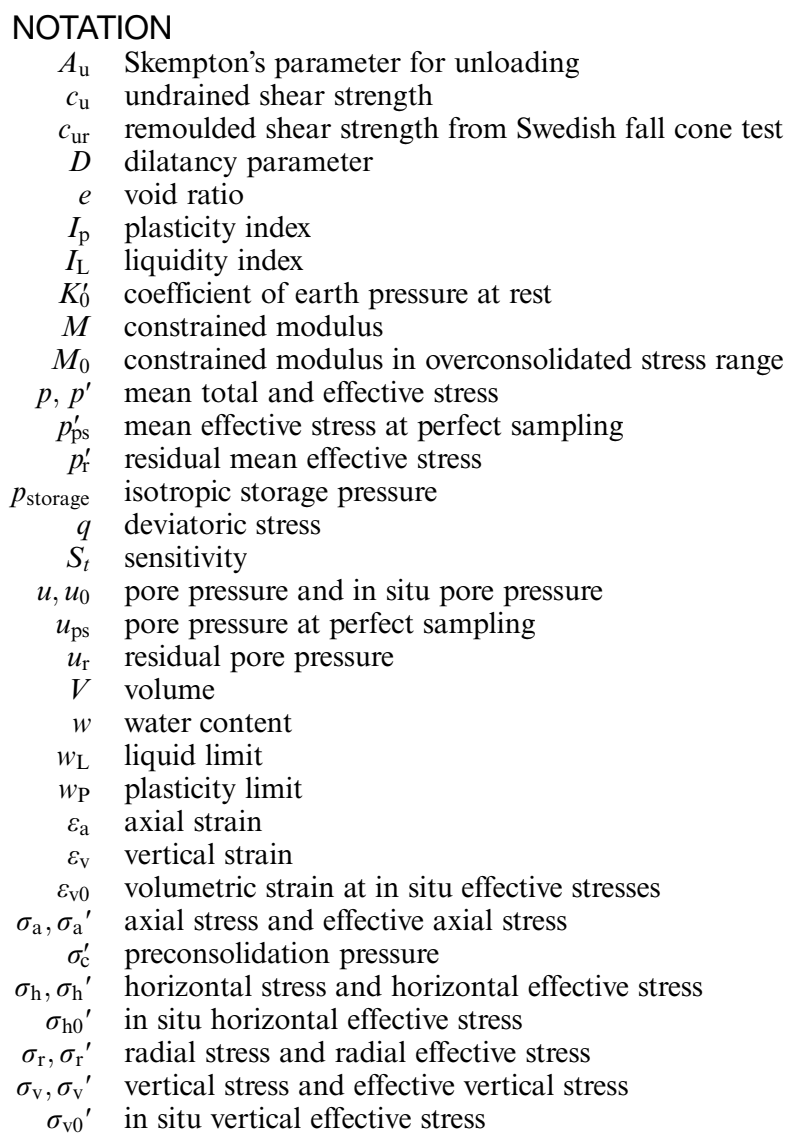

\section{INTRODUCTION}

Avoiding sample disturbance during sampling and maintaining an acceptable sample quality has been the topic of

Manuscript received 17 May 2021; accepted 3 June 2021.

Published online at www.geotechniqueletters.com on 30 July 2021.

*Sweco Norge AS, Trondheim, Norway

(Orcid:0000-0001-9618-3443).

$†$ Norges Teknisk-Naturvitenskapelige Universitet Fakultet for Ingeniorvitenskap, Trondheim, Norway. research for several years (e.g. La Rochelle \& Lefebvre, 1971; Lessard \& Mitchell, 1985; La Rochelle et al., 1986, among others). Block sampling has been proven to be the best method of sampling sensitive clay samples while maintaining high quality (e.g. Lacasse et al., 1985; Hight et al., 1992; Lunne et al., 1997; DeGroot et al., 2003; Tanaka, 2008; Emdal et al., 2016). The block sampling technique (Sherbrooke-type of block samplers) ensures that the sensitive clay remains unaffected by shear distortion from the sampling tube (e.g. Lefebvre \& Poulin, 1979; Hight et al., 1992). However, extraction of a block sample from the ground changes the stress conditions of the soil from in situ to zero total stress. A saturated clay sample reacts to this change with a suction that compensates for the stress change and retains the mean effective stress or suction, at least a fraction of it (e.g. Amundsen et al., 2020). With time, the suction will dissipate and the sample will experience a stress relief that may cause an additional sample disturbance. The effects of storage often include changes in mechanical and chemical properties of the samples.

Mechanical changes during storage are presented in Fig. 1, which show a summary of the previous studies where the peak undrained shear strength $c_{\mathrm{u}}$ and preconsolidation pressure $\sigma_{\mathrm{c}}^{\prime}$ were investigated during a storage period of a few days to several months. Tube and piston samples show a significant decrease in both $c_{\mathrm{u}}$ and $\sigma_{\mathrm{c}}^{\prime}$ during storage. Arman \& McManis (1976) tested extruded tube samples stored for a year and observed significant decreases in both preconsolidation pressure and undrained shear strength of about 29 and 62\%, respectively. Amundsen \& Thakur (2018) tested quick clay samples that were stored inside their sampling tubes and observed that about 5 months of storage may result in a loss of about $17 \%$ of $\sigma_{\mathrm{c}}^{\prime}$ and about $29 \%$ of $c_{\mathrm{u}}$. In block samples, the reduction in $c_{\mathrm{u}}$ and $\sigma_{\mathrm{c}}^{\prime}$ has been observed to be about $10-21$ and $4.8 \%$, respectively (Bozozuk, 1971; La Rochelle et al., 1976). The data show that piston and tube samples are more affected by the storage time compared with block samples, presumably due to an extensive destructuration of soil structure during sampling and extrusion from the sampling tube (e.g. Ladd \& Lambe, 1963; Baligh et al., 1987; Ladd \& DeGroot, 2003). However, most of the early studies on the effects of storage on the mechanical properties were limited to reference testing after a few days or weeks in storage, after the samples were 


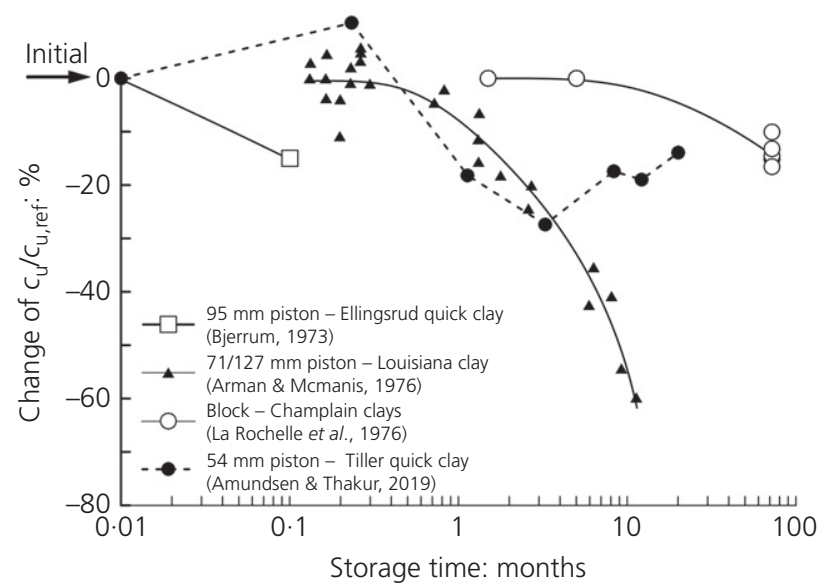

(a)

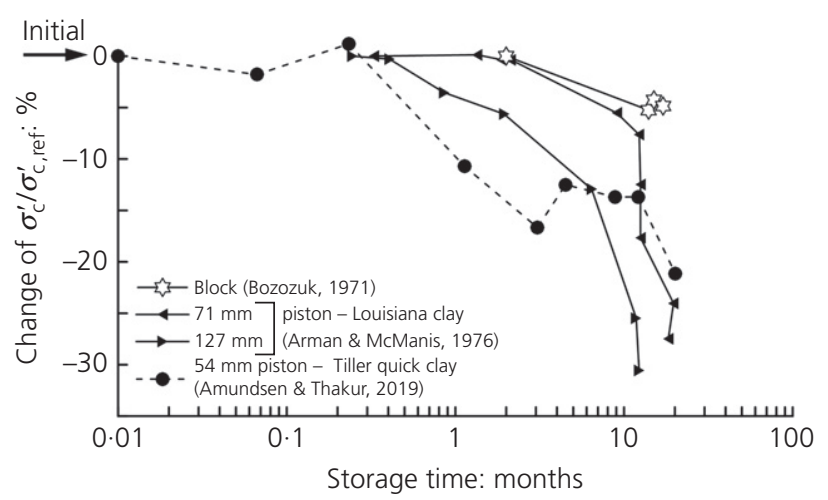

(b)

Fig. 1. Change in normalised (a) peak undrained shear strength $\left(c_{\mathrm{u}} / c_{\mathrm{u}, \text { ref }}\right)$ and (b) preconsolidation pressure $\left(\sigma_{\mathrm{c}}^{\prime} / \sigma_{\mathrm{c}, \text { ref }}^{\prime}\right) . c_{\mathrm{u}, \text { ref }}$ and $\sigma_{\mathrm{c}, \text { ref }}^{\prime}$ are averages of several tests with the least amount of storage time. Data are from Bozozuk (1971), Bjerrum (1973), Arman \& McManis (1976), La Rochelle et al. (1976) and Amundsen \& Thakur (2019)

transported to a laboratory. This study provides results that were obtained from samples that were tested on the site less than an hour after sampling, which eliminates a potential disturbance due to transport and handling. In addition, this paper presents a new method for sealing and storing of block samples that attempts to reduce/minimise the effects of stress relief and ageing of the soil during storage. The method consists of sealing the sample with a rubber membrane and applying an isotropic pressure. The pressurised rubber membrane minimises the amount of air near the surface of the sample and reduces oxidation of the minerals during storage, which is the major cause of ageing (Lessard \& Mitchell, 1985). During storage, the pressure is maintained constant and the sample is allowed to drain the excess water, which presumably comes from the remoulded and disturbed clay at the surface of the samples. The samples were stored and tested at the site 2-65 $\mathrm{d}$ after sampling.

\section{THEORETICAL BACKGROUND}

When a soil sample is extracted from the ground, the total in situ stress reduces to zero. Hence, one would expect an elastic volumetric expansion of the sample. This expansion is, however, prevented by a negative pore pressure that develops in the soil (Ladd \& Lambe, 1963; Skempton \& Sowa, 1963). The difference in pressure transports porewater from the surface of the sample, which is destructured and remoulded, to the undisturbed clay in the core of the sample. This causes, with time, swelling of the sample and dissipation of the negative pore pressure (e.g. Schjetne, 1971), and should be avoided, as it may cause a change in the strength and stiffness properties of the soil sample.

During sampling, the in situ anisotropic stress condition of a soil sample changes into an isotropic stress state. If the soil sample is otherwise undisturbed, the sampling is considered perfect (see Fig. 2). According to Ladd \& Lambe (1963), the pore pressure after a perfect sampling should be

$$
u_{\mathrm{ps}}=-\sigma_{\mathrm{v} 0}^{\prime}\left[K_{0}^{\prime}+A_{\mathrm{u}}\left(1-K_{0}^{\prime}\right)\right]
$$

where $\sigma_{\mathrm{v} 0}^{\prime}$ is the in situ vertical effective stress, $K_{0}^{\prime}$ is the coefficient of earth pressure at rest and $A_{\mathrm{u}}=$ $\left(\Delta u-\Delta \sigma_{\mathrm{h}}\right) /\left(\Delta \sigma_{\mathrm{v}}-\Delta \sigma_{\mathrm{h}}\right)$ is the pore-pressure coefficient, which is between $-0 \cdot 1$ and $0 \cdot 3$, and $1 / 3$ for an elastic response. Therefore, the theoretical mean effective stress, $p_{\mathrm{ps}}^{\prime}$, in a sample after the sampling should be

$$
p_{\mathrm{ps}}^{\prime}=\frac{\sigma_{\mathrm{v} 0}^{\prime}\left(1+2 K_{0}^{\prime}\right)}{3}=-u_{\mathrm{ps}}
$$

where an elastic response is assumed.

The low-plasticity clays and non-plastic soils will not follow a perfect sampling path during sampling, but rather a path of residual effective stress, $p_{\mathrm{r}}^{\prime}$ (see Fig. 2) (e.g. Hight, 2001; Amundsen et al., 2020).

\section{MATERIALS}

The samples that were used in this study were extracted from about $10 \mathrm{~m}$ depth at the Tiller research site. The area has been used for research purposes by the Norwegian University of Science and Technology (NTNU) for several years - for example, Sandven (1990); Gylland et al. (2013); Amundsen et al. (2017); among others. The samples consisted of a high-sensitive marine quick clay with sensitivity $S_{t}=234$ and remoulded shear strength $c_{\text {ur }} \leq 0.1 \mathrm{kPa}$. The material is normally to slightly overconsolidated $(\mathrm{OCR}=1 \cdot 7)$.

The layering of the Tiller quick clay was investigated in detail by scanning a sampling tube prior to extrusion. Figure 3(a) shows the X-ray image of a sample from $10 \cdot 0$ to $10 \cdot 8 \mathrm{~m}$. After the scanning, the sample was opened and divided into 246 thin slices of about $3 \mathrm{~mm}$ in thickness; the natural water content was determined. The results show that the natural water content varies between 25 and $51 \%$, with an average of $38.2 \%$. The variations in water content match the layering that was captured by the X-ray image. The darker layers have a lower water content, indicating a higher silt content, and the lighter layers have a high water content, indicating a higher clay content. To confirm these observations, three layers of different water contents were chosen for further testing. The layers are marked in Fig. 3(a). Layer 1 has an average water content of $29 \cdot 3 \%$, layer 2 has $37 \cdot 2 \%$ and layer 3 has $46 \cdot 5 \%$. First, the Atterberg limits were determined for the samples, followed by a determination of the grain-size distribution. The results in Fig. 3(c) show a clear correlation between the plasticity index, water content and clay content $(\%$ of the particles $<2 \mu \mathrm{m})$. Layer 1 , with the lowest water content $(29 \cdot 3 \%)$, correspondingly had the lowest plasticity $(4.9 \%)$ and the highest silt content $(66 \%)$.

\section{METHODOLOGY}

The samples in this study were taken by using a downsized version of the Sherbrooke block sampler $(160 \mathrm{~mm}$ wide and 300-350 mm high), also called the mini-block sampler, made at the NTNU (Emdal et al., 2016). 


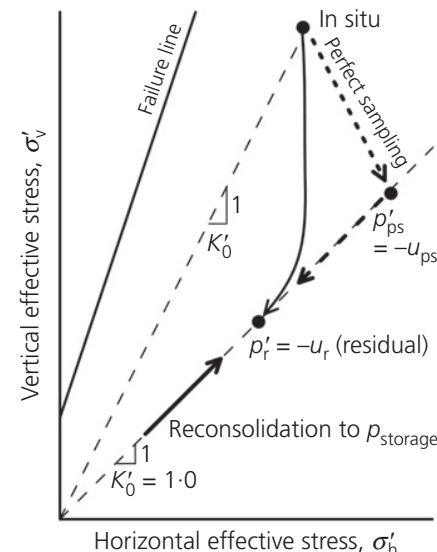

(a)

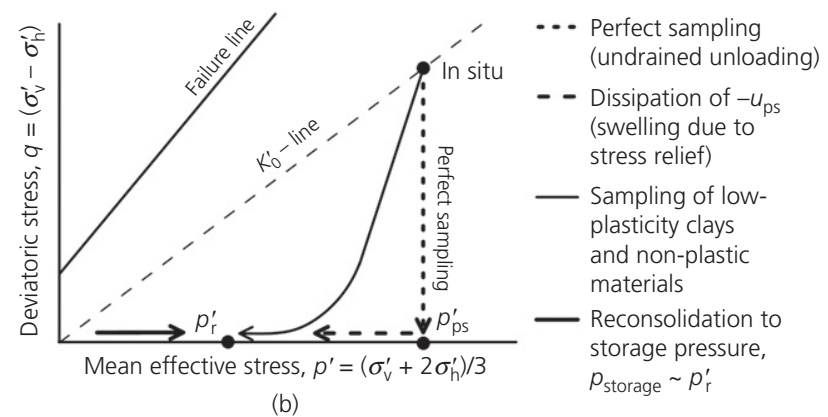

(b)

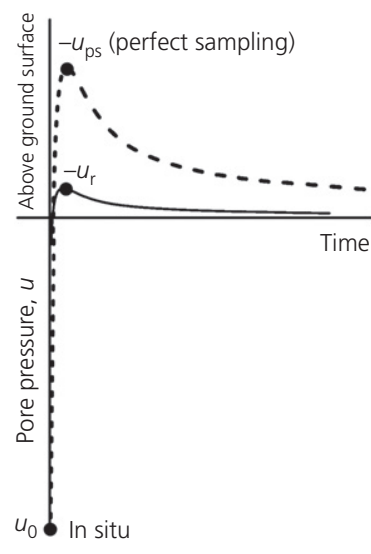

(c)
Fig. 2. Sampling-induced stress changes of a saturated block sample in (a) $\sigma_{\mathrm{h}}^{\prime}-\sigma_{\mathrm{v}}^{\prime}$ stress space and (b) $p^{\prime}-q$ stress space and (c) dissipation of pore pressure with time. Perfect sampling: $p_{\mathrm{ps}}^{\prime}$ is the mean effective stress and $u_{\mathrm{ps}}$ is the negative pore pressure. Sampling: $p_{\mathrm{r}}^{\prime}$ is the residual mean effective stress and $u_{\mathrm{r}}$ is the negative residual pore pressure or suction. Storage: $p_{\text {storage }}$ is the isotropic storage pressure (source: adapted from Amundsen et al. (2020))

The pressurised storage cell (PSC) was developed and built at the NTNU. Figure 4(a) shows the cross-section of the PSC that consists of a footing (1) with a pedestal (2), where the mini-block sample is placed $(160 \mathrm{~mm}$ wide, cut to $300 \mathrm{~mm}$ high). The sample is covered with filter paper (3) on the top and bottom. The rubber membrane (4) seals the sample with O-rings (5) to the top cap (6) and pedestal (2). Thereafter, the sample is covered with the cylinder (7) and locked to the pedestal (2) with six screws (9). The cylinder is locked using a lid (8) with two outlets, one for the water (10) to fill up the cell and the second outlet for the pressure control system (11). The drainage tube (12) allows the excess water to drain and be monitored during storage. The storage pressure was set to be less than half of the in situ mean effective stress (about $0.4 p_{0}^{\prime}$ ) and was maintained constant during storage. Storage pressure attempts to maintain the isotropic stress that a sample experiences after sampling (see Fig. 3), which are lower than the in situ stress conditions.

Sealing and applying pressure on a sample inside the storage cell was conducted at the site, shortly after sampling. The PSC was stored inside the field laboratory (developed and made by the Norwegian Public Road Administration or NPRA), which was placed at the Tiller research site throughout the storage period. In an attempt to evaluate the effect of the PSC, a set of mini-block samples was stored without a PSC. Samples were sealed using several layers of household plastic film (PF). After the storage periods, block samples were opened and tested at the NPRA field laboratory. None of the samples was transported, except for PF4 and PSC4; however, none of the advanced tests was conducted on those samples.

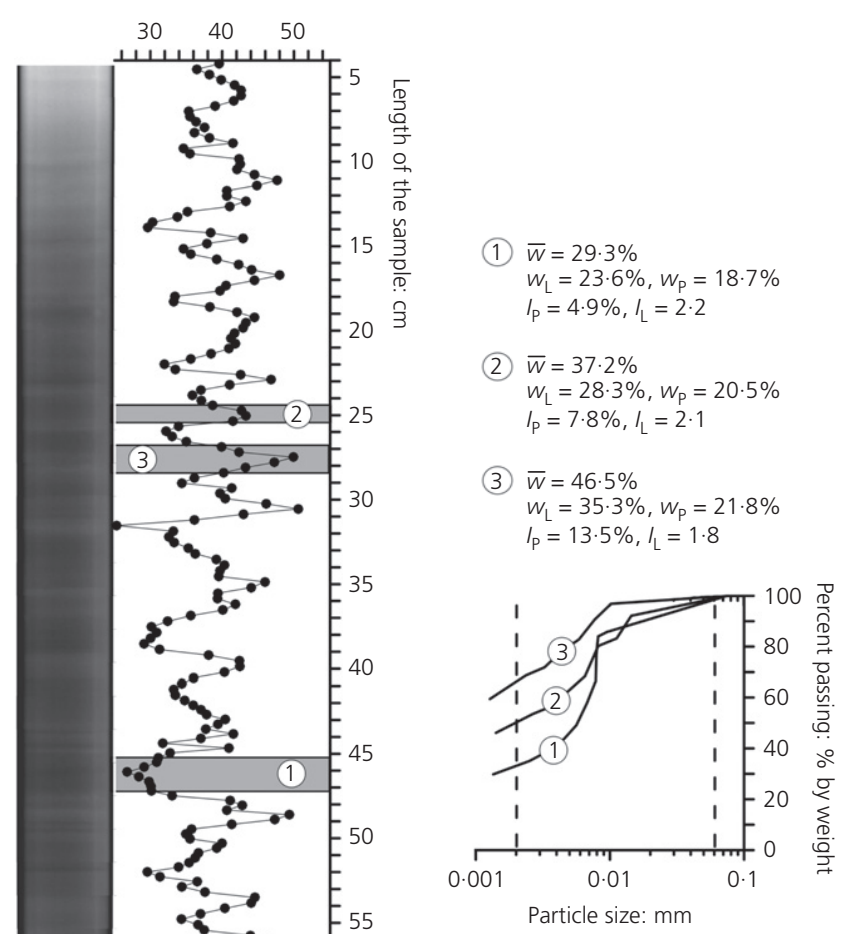

(b)

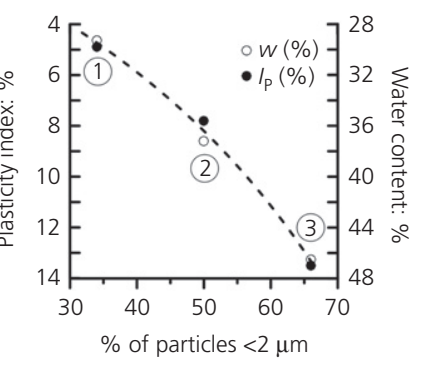

(b)

Fig. 3. (a) X-ray image of a $54 \mathrm{~mm}$ piston sample of quick clay with its natural water content; (b) grain-size distribution; (c) correlation between the plasticity index, water content and the $\%$ of particles $<2 \mu \mathrm{m}$

The conducted tests were as follows: water content $(w)$, remoulded shear strength $\left(c_{\mathrm{ur}}\right)$, pore water chemistry, constant rate of strain (CRS) oedometer tests and anisotropically consolidated triaxial tests that were sheared undrained (CAUC). The soil specimens were cut out and trimmed to $20 \mathrm{~mm}$ high and $50 \mathrm{~mm}$ wide for oedometer tests, and $100 \mathrm{~mm}$ high and $54 \mathrm{~mm}$ wide for the triaxial tests. The oedometer tests were conducted with a strain rate of $1.0 \% / \mathrm{h}$, and the triaxial tests were consolidated isotropically with $1.0 \mathrm{kPa} / \mathrm{min}$ and anisotropically with about $0.08 \mathrm{kPa} / \mathrm{min}$. The specimens were sheared with $1.5 \% / \mathrm{h}$ after about $1 \mathrm{~d}$ of consolidation.

\section{RESULTS AND DISCUSSION}

Three sets of samples were analysed, a reference sample, samples that were stored inside the PSC and samples that were sealed with a plastic film (PF-samples). A summary of the samples that were tested in this study is shown in Table 1. The reference block sample was tested shortly after the sampling at the NPRA field laboratory, about $0 \cdot 5-2 \mathrm{~h}$ after the sample was extracted from the ground. Six samples were stored at the site for $2-43 \mathrm{~d}$ prior to testing at the site and two samples were transported to the laboratory prior to storage of $61-65 \mathrm{~d}$. The volumetric strain $\Delta V / V_{0}$ of the 


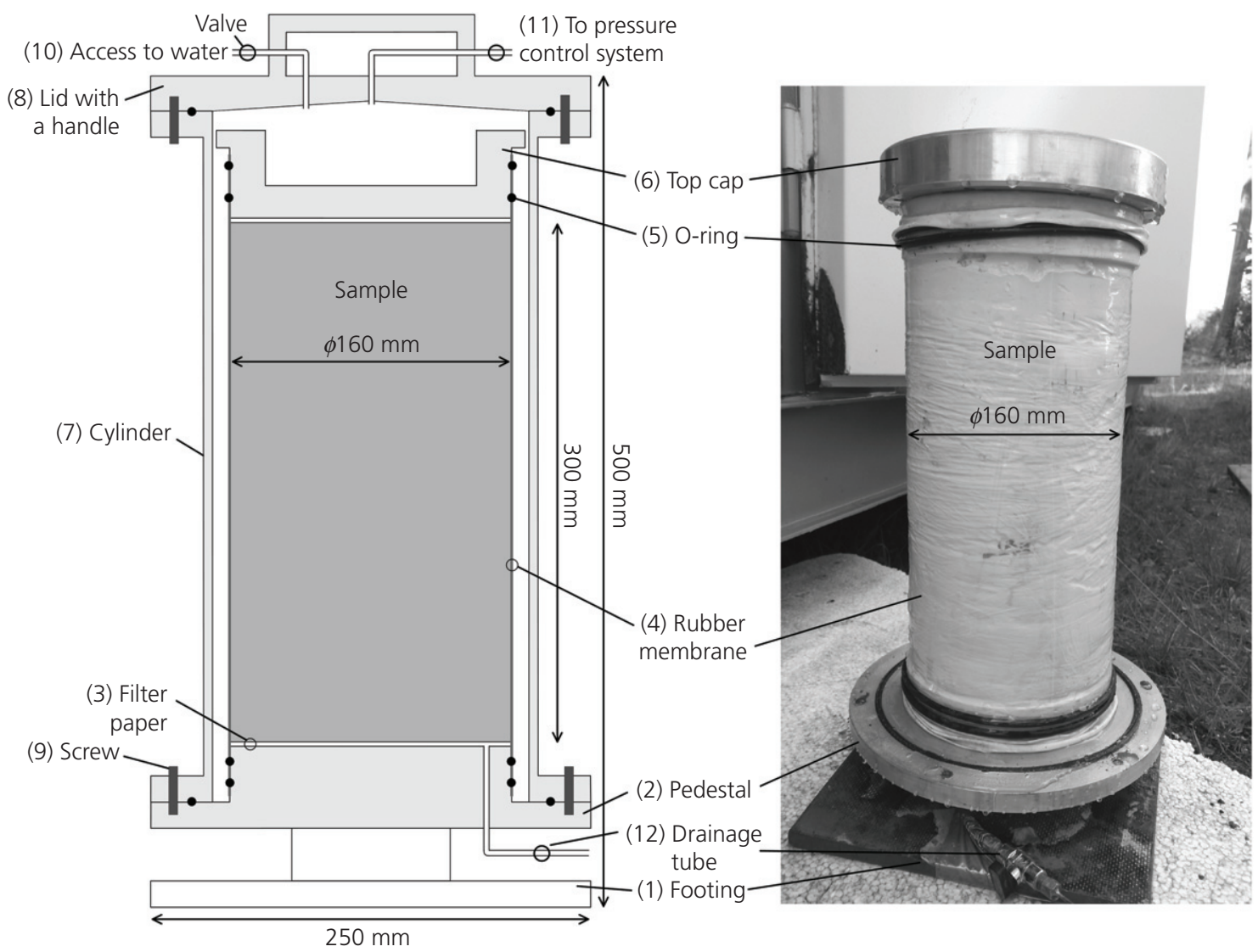

(a)

(b)

Fig. 4. (a) Cross-section of the PSC developed and made at the NTNU; (b) a mini-block sample, sealed with a rubber membrane and O-rings, after storage inside the PSC

Table 1. Overview of the mini-block samples from the Tiller site used in this study

\begin{tabular}{|c|c|c|c|c|c|c|c|}
\hline Sample & Storage: $\mathrm{d}$ & Borehole & Depth: $\mathrm{m}$ & $\sigma_{\mathrm{v} 0}^{\prime}: \mathrm{kPa}$ & $p_{0}^{\prime}: \mathrm{kPa}$ & $p_{\text {storage }}: \mathrm{kPa}$ & $\Delta V / V_{0}: \%$ \\
\hline Ref. & 0 & МBH09 & $10 \cdot 45-10 \cdot 80$ & 102 & 68 & 0 & - \\
\hline PF1 & 2 & MBH05 & $9 \cdot 40-9 \cdot 75$ & 93 & 62 & 0 & - \\
\hline PF2 & 11 & МBH09 & $9 \cdot 50-9 \cdot 85$ & 97 & 65 & 0 & - \\
\hline PF3 & 31 & MBH08 & $10 \cdot 35-10 \cdot 60$ & 101 & 67 & 0 & - \\
\hline PF4* & 65 & MBH08 & $10 \cdot 70-11 \cdot 05$ & 104 & 69 & 0 & - \\
\hline PSC1 & 3 & МBH09 & $11 \cdot 50-11 \cdot 85$ & 112 & 75 & 30 & $0 \cdot 010$ \\
\hline PSC2 & 9 & МBH09 & $9 \cdot 85-10 \cdot 25$ & 97 & 65 & 28 & $0 \cdot 155$ \\
\hline PSC3 & 43 & MBH09 & $11 \cdot 85-12 \cdot 20$ & 115 & 86 & 33 & $0 \cdot 423$ \\
\hline PSC4* & 61 & МBH08 & $11 \cdot 05-11 \cdot 40$ & 108 & 72 & 30 & - \\
\hline
\end{tabular}

All samples, except for PF4 and PSC4, were stored and tested at the sampling site. $\sigma_{\mathrm{v} 0}^{\prime}$, in situ vertical effective stress; $p_{0}^{\prime}$, in situ mean effective stress $\left(K_{0}^{\prime}=0.5\right) ; p_{\text {storage, }}$, isotropic storage pressure; $\Delta V / V_{0}$, volumetric strain; PF, sealed with a plastic film; PSC, pressurised storage cell *Transported samples

samples PSC1-3 was monitored throughout the storage of 3,9 and $43 \mathrm{~d}$ and the results are shown in Fig. 5. The short-term storage of 3 and $9 \mathrm{~d}$ resulted in a negligible volumetric strain of $0 \cdot 10$ and $0 \cdot 15 \%$. The storage of $43 \mathrm{~d}$ resulted in a larger volumetric strain of $0.42 \%$, but the sample still classified as of high quality (Lunne et al., 1997). Sample PSC4 was allowed to drain water during storage, but the volumetric strain was not measured. It was noted that the drainage tube was not dry when the sample was opened and tested.

Figure 6 shows the measured water content, remoulded shear strength, $\mathrm{pH}$ and sum of cation concentrations in all nine samples. The shaded area in the figure represents the range of values of $0 \mathrm{~d}$ samples. Note that the measured values are in the upper range shown in Fig. 4. The results indicate that all mini-block samples, that were stored either

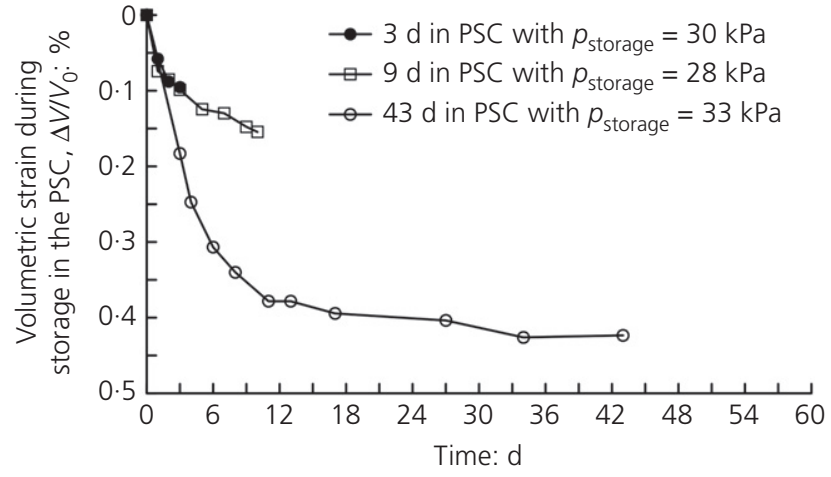

Fig. 5. Volumetric strain $\Delta V / V_{0}$ of the mini-block samples stored in the PSC with a $p_{\text {storage }}$ isotropic pressure. PSC, pressurised storage cell 


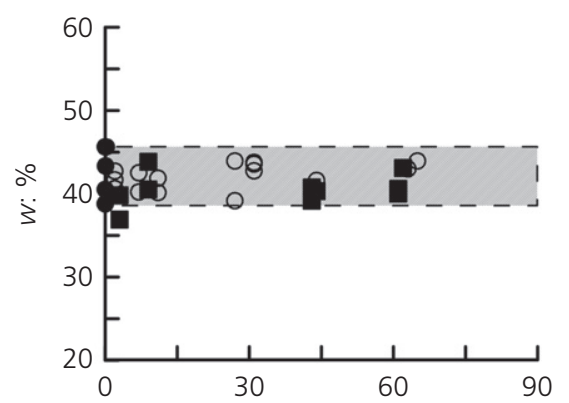

(a)

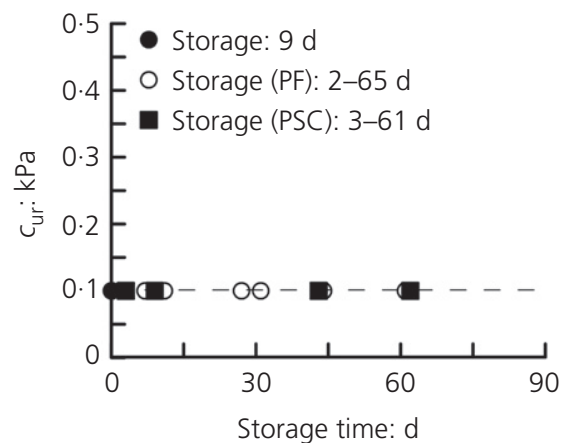

(b)

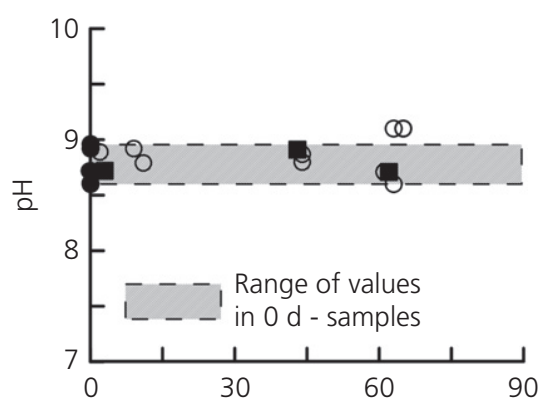

(c)

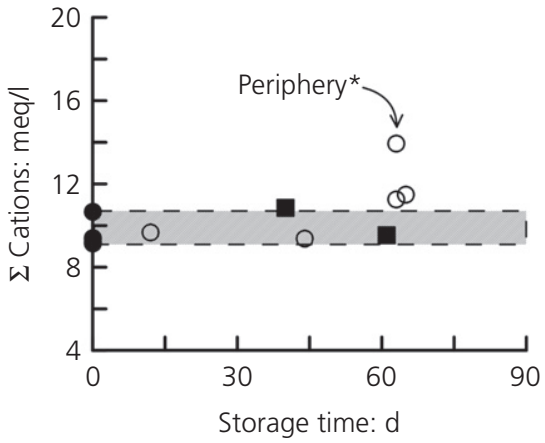

(d)

Fig. 6. Variation in (a) water content $(w)$; (b) remoulded shear strength $\left(c_{\mathrm{ur}}\right)$; (c) $\mathrm{pH}$ and (d) sum of cation concentrations during the storage of mini-block samples. Samples were either tested immediately after sampling or sealed and stored. PF, sealed with a plastic film; PSC, pressurised storage cell

in the PSC or sealed with a PF, show no changes in water content or remoulded shear strength as the measured values are within the range of scatter of natural variation. This is in agreement with the negligible volumetric strain that was measured during storage (see Fig. 5).

According to Lessard \& Mitchell (1985), it is expected that both block and extruded tube samples that are stored for more than 2 months show the signs of ageing when they are not properly sealed. Typical signs of ageing are an increase in remoulded shear strength, $\mathrm{pH}$ and sum of cations (Lessard \& Mitchell, 1985). The measured remoulded shear strength was constant for all samples, regardless of the storage period and conditions (see Fig. 6(b)). The $\mathrm{pH}$ values and the sum of cation concentrations show some minor changes in the PF-samples after 2 months of storage, especially at the periphery of the sample (see Fig. 6(d)). The samples that were stored in the PSC (see Fig. 6), showed no changes during storage. This indicates that clay samples can be sealed with the use of a PF as long as the storage period is a few months.

The comparison between test results of the reference sample, PSC-samples and PF-samples is shown in Figs. 7-9. The results indicate that the storage of the mini-block samples inside the PSC has halted the decrease of $c_{\mathrm{u}}$, which would have reduced by $6-13 \%$. The $\sigma_{\mathrm{c}}^{\prime}$ reduces by $16-23 \%$ in the samples sealed with a PF; however, the PSC-samples remain close to the range of $0 \mathrm{~d}$ samples during storage. It appears that the PSC is able to preserve $c_{\mathrm{u}}$ and $\sigma_{\mathrm{c}}^{\prime}$ during storage. Note that some of the $c_{\mathrm{u}}$ values (PSC) are slightly above the range of values of $0 \mathrm{~d}$ samples as shown in Fig. 9(a). The increase in $c_{\mathrm{u}}$ is only $2 \%$ and therefore assumed to be within the natural variation in the soil. The PF-samples, on the contrary, show a clearer change in $c_{\mathrm{u}}$ during storage. Other parameters derived from the triaxial and oedometer tests, such as dilatancy parameter $D$ and constrained modulus $M_{0}$, which are usually affected by the sample disturbance (e.g. Lunne et al., 1997; Karlsrud \& Hernandez-Martinez, 2013), have not been significantly influenced by the storage in the PSC compared with the storage in a PF (see Fig. 9). $M_{0}$ reduced by about $22-33 \%$ in the PF-samples and exhibited a more contractile behaviour prior to failure $(D<0)$.

The block samples that were sealed with a PF showed a reduction in the peak undrained shear strength of about $6-13 \%$ after 2 months of storage. The reduction in strength is more significant when the Tiller quick clay was stored inside the sampling tubes, which resulted in an 18-29\% reduction after 1-3 months of storage (see Fig. 1 and Amundsen \& Thakur, 2019). The reduction is even greater, by about $41-48 \%$, when comparing a $0 \mathrm{~d}$ block sample with a sample stored in a $54 \mathrm{~mm}$ tube. This illustrates the significance of high-quality sampling and the importance of testing the clay shortly after sampling.

The quality of the tested samples, according to the $\Delta e / e_{0}$ criterion (Lunne et al., 1997), is summarised in Figs. 9(c) and 9(f). The results indicate that the storage of the PFsamples deteriorates their quality. However, the samples that were stored in the PSC exhibited quality that is closer to that of $0 \mathrm{~d}$ samples. This indicates an improvement of the sample quality when samples are stored in the PSC.

Some of the observed changes can be caused by natural variation in the clay; however, the number of tests that were conducted on stored samples indicates that there is a systematic decrease in mechanical properties during the storage of mini-block samples, as shown in Fig. 9. The results are similar to an observation reported by Bjerrum (1973) where the $c_{\mathrm{u}}$ reduced by $15 \%$ after $3 \mathrm{~d}$ in a $95 \mathrm{~mm}$ sampling tube, and an extensive study conducted by Amundsen \& Thakur (2019) where the $c_{\mathrm{u}}$ decreased by $18 \%$ after a month in $54 \mathrm{~mm}$ sampling tubes. This indicates that the support of the sampling tube or high-quality block sampling is not enough to preserve the mechanical properties of the normally consolidated high-sensitive marine clays of low plasticity and that a constant pressure is necessary to preserve the mechanical properties of the clay. More research is, however, needed to determine the optimum magnitude of 
(a), (b) CAUC tests

- $0 \mathrm{~d}(0.5 \mathrm{~h})$ - CAUC, $10.5 \mathrm{~m}$

- $2 \mathrm{~d}$ in PF-CAUC, $11.7 \mathrm{~m}$

--- $3 \mathrm{~d}$ in PSC - CAUC, $9.6 \mathrm{~m}$

(c), (d) CAUC tests

- $0 \mathrm{~d}(0.5 \mathrm{~h})$ - CAUC, $10.5 \mathrm{~m}$

- $11 \mathrm{~d}$ in PF - CAUC, $9.6 \mathrm{~m}$

--- $9 \mathrm{~d}$ in PSC - CAUC, $10.0 \mathrm{~m}$

(e), (f) CAUC tests

— $0 \mathrm{~d}(0.5 \mathrm{~h})$ - CAUC, $10.5 \mathrm{~m}$

- $31 \mathrm{~d}$ in PF - CAUC, $10.4 \mathrm{~m}$

--- $43 \mathrm{~d}$ in PSC - CAUC, $12.0 \mathrm{~m}$

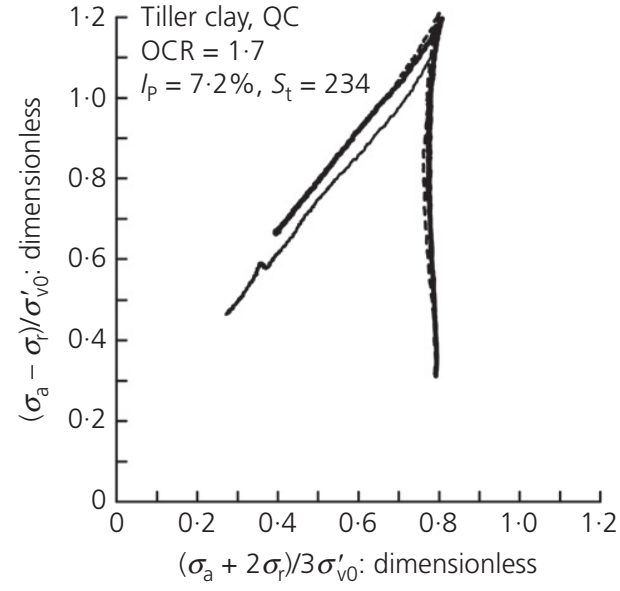

(a)

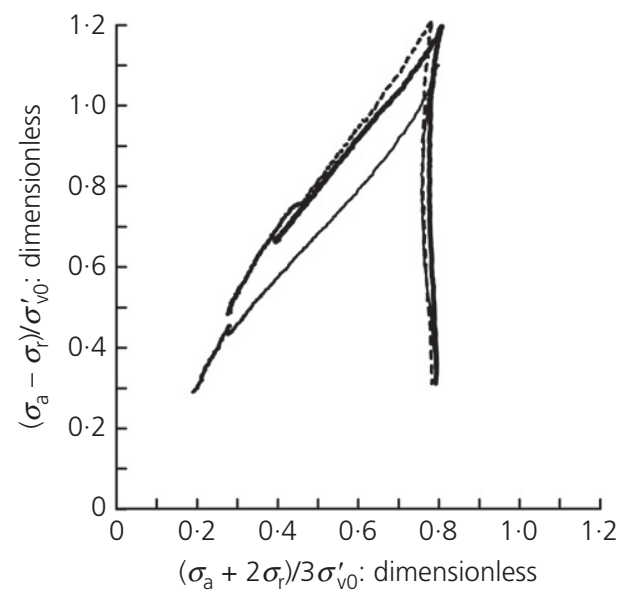

(c)

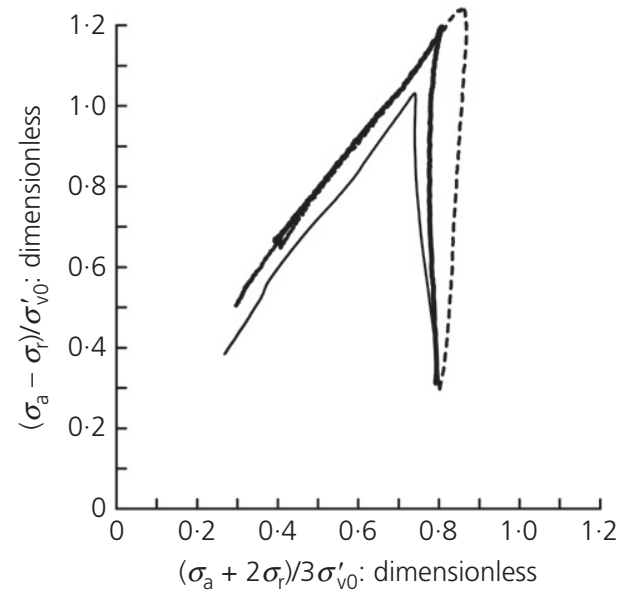

(e)

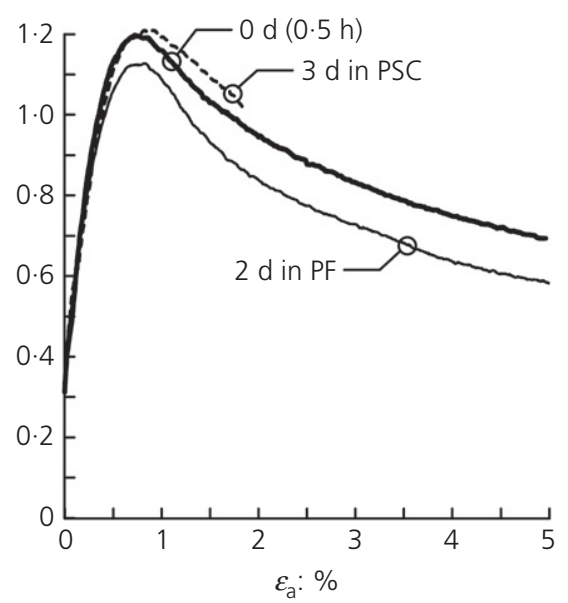

(b)

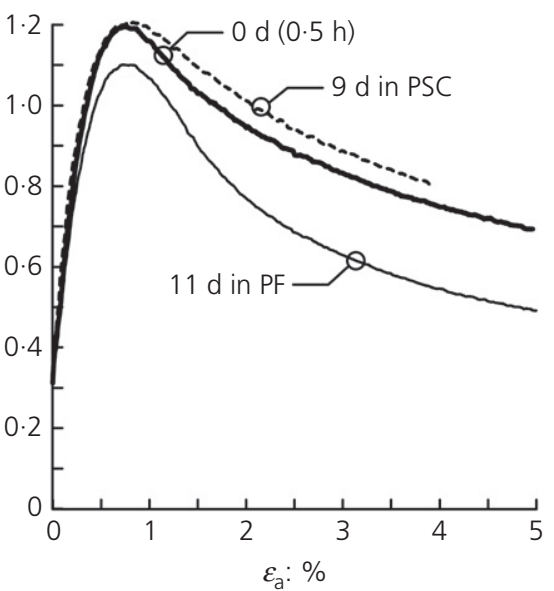

(d)

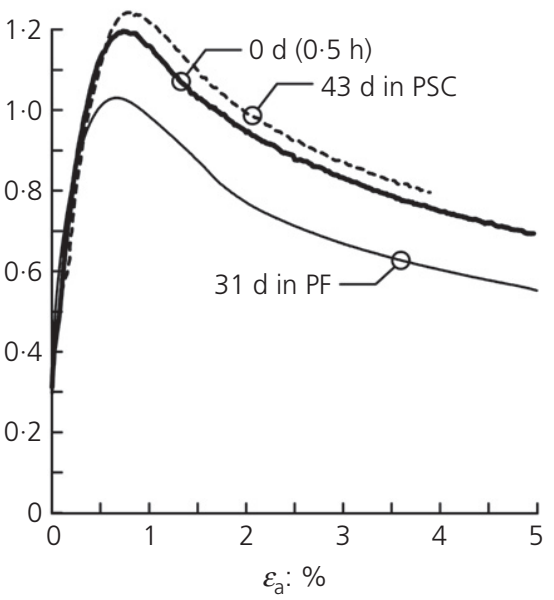

(f)

Fig. 7. Effect of storage on triaxial test (CAUC) results of mini-block samples. Samples were sealed either with a plastic film (marked $\mathrm{PF}$ ) or with the pressurised storage cell (marked PSC)

the storage pressure and the maximum storage time. Equipment and technique can be modified to make PSCs easy to transport without risking the quality of the samples. The conducted tests show that the proposed method of storing samples is able to minimise the effects of stress relief and storage.

\section{CONCLUSION}

A new method has been developed for storage of mini-block samples using a PSC. In the storage cell, the sample is sealed with a rubber membrane and stored under drained conditions with a constant isotropic storage pressure of about $40 \%$ of the in situ mean effective stress.

The results indicate that water content, remoulded shear strength, $\mathrm{pH}$ and sum of cations are constant or within the range of natural variation, during storage of up to 2 months in the PSC. Some minor/negligible changes are observed in samples that were sealed with a PF, which indicate that the ageing process has begun in the soil. It is, therefore, concluded that block samples can be stored inside the PF only for a few months before measurable ageing of the clay occurs. 
(a) CRS tests

- $0 \mathrm{~d}(2 \mathrm{~h})-\mathrm{CRS}, 9.9 \mathrm{~m}$

- $2 \mathrm{~d}$ in PF-CRS, $9.4 \mathrm{~m}$

-. - $3 \mathrm{~d}$ in PSC - CRS, $11.7 \mathrm{~m}$

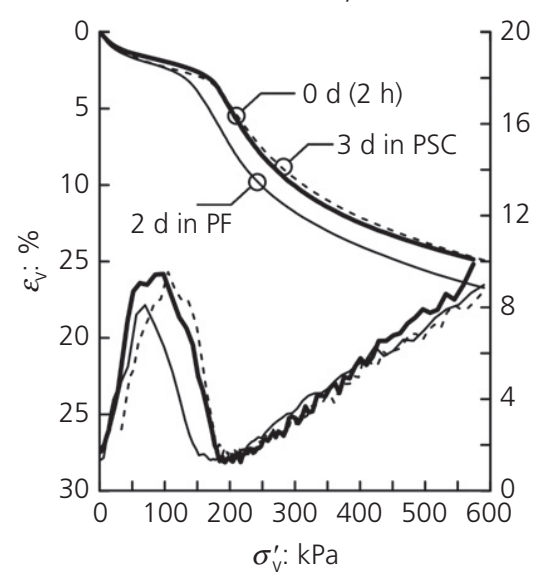

(a) (b) CRS tests

— $0 \mathrm{~d}(2 \mathrm{~h})-\mathrm{CRS}, 9.9 \mathrm{~m}$

- $11 \mathrm{~d}$ in PF - CRS, $9.6 \mathrm{~m}$ ... $9 \mathrm{~d}$ in PSC - CRS, $10.0 \mathrm{~m}$

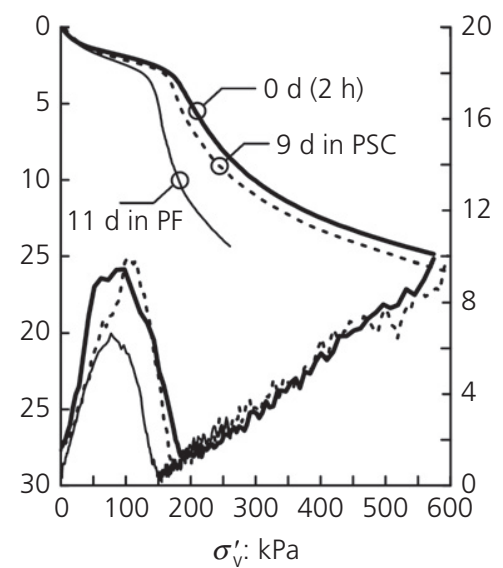

(b) (c) CRS tests

— $0 \mathrm{~d}(2 \mathrm{~h})-\mathrm{CRS}, 9.9 \mathrm{~m}$

- $31 \mathrm{~d}$ in PF-CRS, $10.5 \mathrm{~m}$ ...43 d in PSC - CRS, $12.0 \mathrm{~m}$

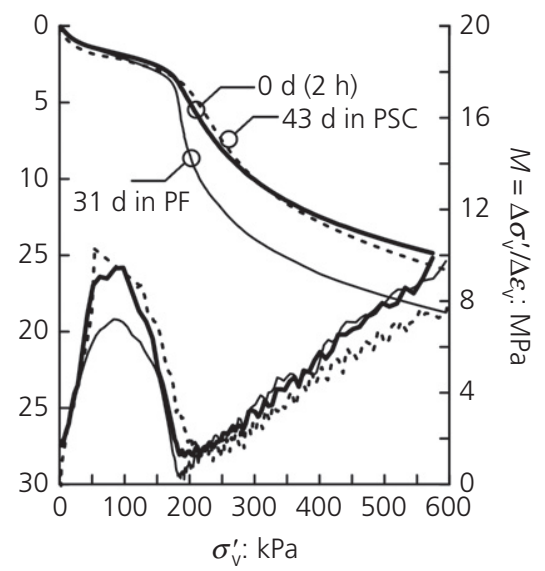

(c)

Fig. 8. Effect of storage on oedometer test (CRS) results of mini-block samples. Samples were sealed either with a plastic film (marked PF) or with the pressurised storage cell (marked PSC)

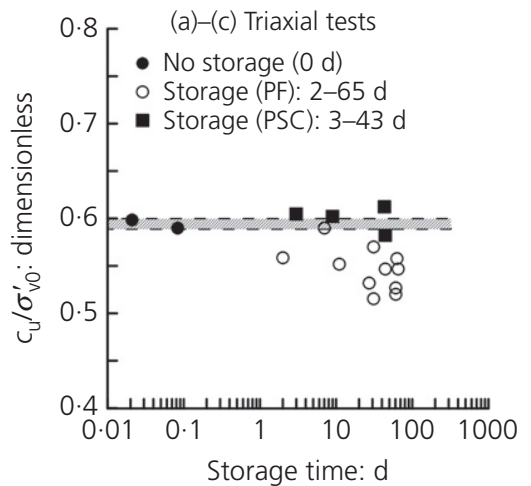

(a)

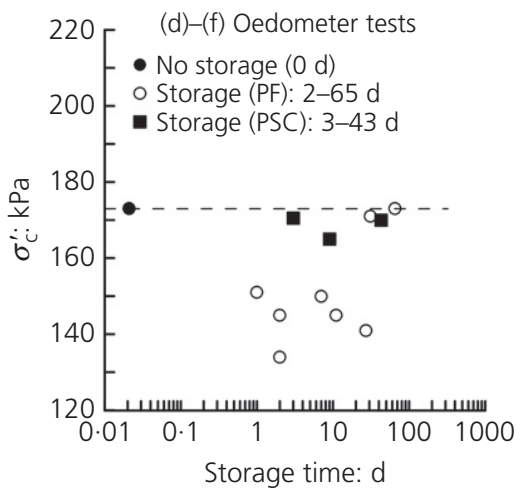

(d)

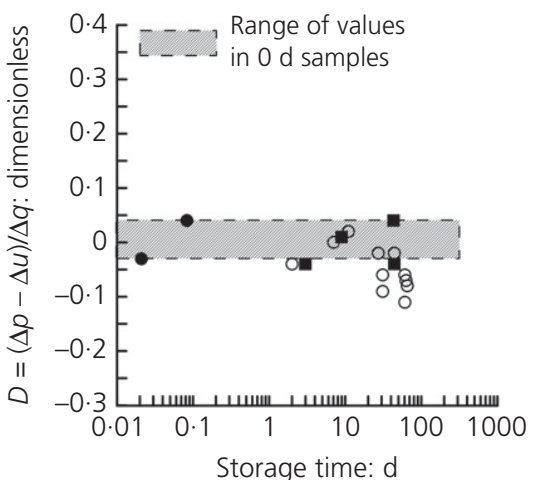

(b)

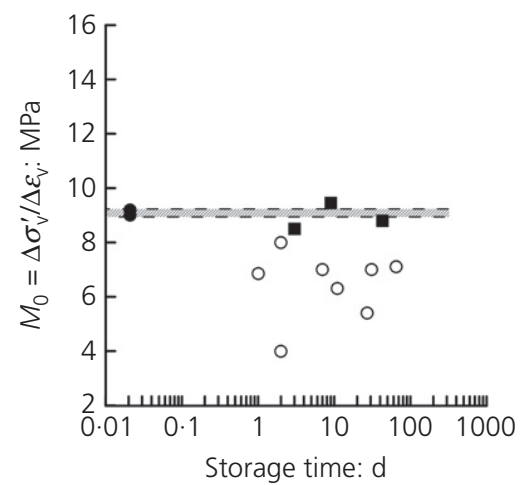

(e)

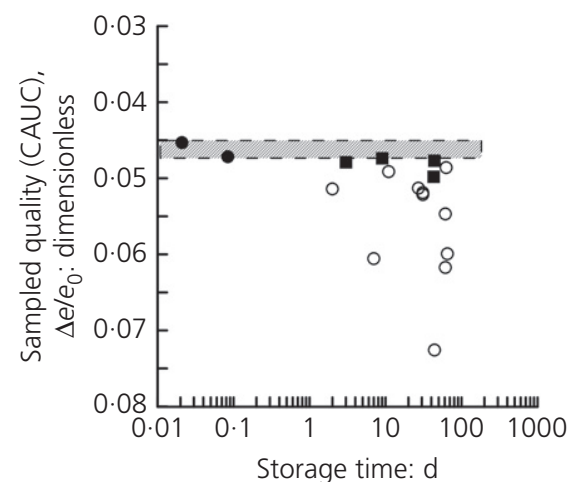

(c)

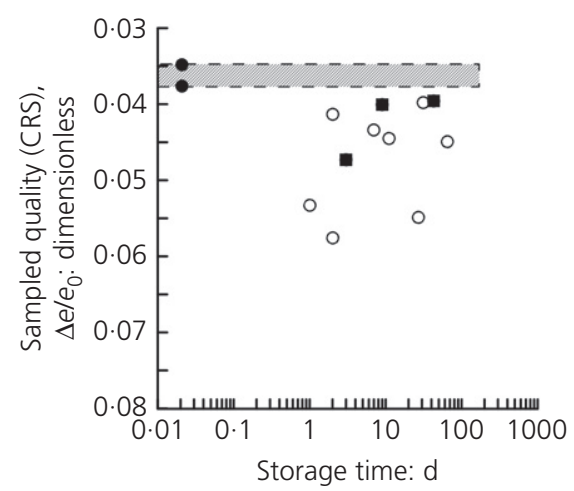

(f)

Fig. 9. Effect of storage on (a)-(c) triaxial test (CAUC) results and (d)-(f) oedometer test (CRS) results. Samples were sealed either with a plastic film (marked PF) or with the pressurised storage cell (marked PSC)

The triaxial and oedometer tests conducted on the PSC-samples indicate that strength and consolidation parameters were close to the $0 \mathrm{~d}$ samples. The PSCsamples seem to have avoided a $6-13 \%$ decrease in undrained shear strength, $16-23 \%$ for the preconsolidation pressure and $22-33 \%$ for the constrained modulus. The sample quality, assessed by using the $\Delta e / e_{0}$ criterion (Lunne et al., 1997), has also improved in the mini-block samples that were stored inside the PSC.
The observed results indicate that the confining isotropic pressure in the PSC provides the support that is needed to preserve some of the effective stress during storage and minimise the stress relief, which has proven to be beneficial with regards to sample quality and material properties. The conducted study is a limited pilot study, but the results are promising. Further research is required to propose recommendations for storage procedures, such as the drainage, optimal storage pressure and maximum storage time. 


\section{ACKNOWLEDGEMENTS}

G. Winther, E. Husby, P. Østensen, K. I. Kvisvik and E. Andersen, engineers at NTNU Geotechnical Division are gratefully acknowledged for their skills and knowledge that made the experimental work possible. The authors acknowledge support from the inter-governmental research programme 'Natural hazards: Infrastructure, Floods and Slides (NIFS, www.naturfare.no, 2012-2015)'. The first author was supported by the Research Council of Norway, grant number 246629 .

\section{REFERENCES}

Amundsen, H. \& Thakur, V. (2018). Storage duration effects on soft clay samples. Geotech. Test. J. 42, No. 4, 1031-1054.

Amundsen, H. A., Jønland, J., Emdal, A. \& Thakur, V. (2017). An attempt to monitor pore pressure changes in a block sample during and after sampling. Géotech. Lett. 7, No. 2, 119-128.

Amundsen, H. A., Emdal, A. \& Thakur, V. (2020). Field and laboratory study of stress relief due to unloading in block samples of sensitive clay. Géotechnique 70, No. 6, 503-517, doi: https://doi.org/10.1680/jgeot.18.P.083.

Arman, A. \& McManis, K. L. (1976). Effect of storage and extrusion on sample properties. In Soil specimen preparation for laboratory testing, ASTM STP 599 (eds D. Sangrey and R. Mitchell), pp. 66-87. West Conshohocken, PA, USA: American Society of Testing and Materials.

Baligh, M., Azzouz, A. \& Chin, C. (1987). Disturbances due to 'Ideal' tube sampling. J. Geotech. Engng 113, No. 7, 739-757.

Bjerrum, L. (1973). Problems of soil mechanics and construction on soft clays. State-of-the-art report. In Proceedings of the 8 th international conference on soil mechanics and foundation engineering, Moscow, Russia, vol. 3, pp. 111-159.

Bozozuk, M. (1971). Effect of sampling, size, and storage on test results for marine clay. In Sampling of soil and rock, ASTM STP 483 (eds B. Gordon and C. Crawford), pp. 121-131. West Conshohocken, PA, USA: American Society for Testing and Materials.

DeGroot, D., Lunne, T., Sheahan, T. \& Ryan, R. (2003). Experience with downhole block sampling in clays using conventional drilling equipment. In Proceedings of the 12th Pan American conference on soil mechanics and geotechnical engineering (eds P. J. Culligan and A. J. Whittle), pp. 521-526. Cambridge, MA, USA: MIT

Emdal, A., Gylland, A., Amundsen, H. A., Kåsin, K. \& Long, M. (2016). Mini-block sampler. Can. Geotech. J. 53, No. 8, $1235-1245$.

Gylland, A., Long, M., Emdal, A. \& Sandven, R. (2013). Characterisation and engineering properties of Tiller clay. Engng Geol. 164, 86-100.

Hight, D. W. (2001). Sampling effects in soft clay: an update on Ladd and Lambe (1963). In ASCE Special geotechnical publication, No. 119, soil behaviour and soft ground construction (eds J. T. Germaine, T. C. Sheahan and R. V. Whitman), pp. 86-121. Reston, Virginia, USA: ASCE.

Hight, D. W., Böese, R., Butcher, A. P., Clayton, C. R. I. \& Smith, P. R. (1992). Disturbance of the bothkennar clay prior to laboratory testing. Géotechnique 42, No. 2, 199-217, https://doi. org/10.1680/geot.1992.42.2.199.

Karlsrud, K. \& Hernandez-Martinez, F. G. (2013). Strength and deformation properties of Norwegian clays from laboratory tests on high-quality block samples. Can. Geotech. J. 50, No. 12, 1273-1293.

La Rochelle, P. \& Lefebvre, G. (1971). Sampling disturbance in Champlain clays. In Sampling of soil and rock, ASTM STP 483 (eds B. Gordon and C. Crawford), pp. 143-163. West Conshohocken, PA, USA: American Society for Testing and Materials.

La Rochelle, P., Sarrailh, J., Roy, M. \& Tavenas, F. A. (1976). Effect of storage and reconsolidation on the properties of Champlain clays. In Soil specimen preparation for laboratory testing, ASTM STP 599 (eds D. Sangrey and R. Mitchell), pp. 126-146. West Conshohocken, PA, USA: American Society for Testing and Materials.

La Rochelle, P., Leroueil, S. \& Tavenas, F. (1986). A technique for long-term storage of clay samples. Can. Geotech. J. 23, No. 4, 602-605.

Lacasse, S., Berre, T. \& Lefevbre, G. (1985). Block sampling of sensitive clays. In Proceedings of the 11th international conference on soil mechanics and geotechnical engineering, vol. 2, pp. 887-892. Rotterdam, the Netherlands: Balkema.

Ladd, C. C. \& DeGroot, D. J. (2003). Recommended practice for soft ground site characterization: Arthur Casagrande lecture. In Proceedings of the 12th Pan American conference on soil mechanics and geotechnical engineering (eds P. J. Culligan, H. H. Einstein and A. J. Whittle), vol. 1, pp. 3-57. Essen, Germany: Verlag Glückauf.

Ladd, C. C. \& Lambe, T. W. (1963). The strength of 'undisturbed' clay determined from undrained tests. In Symposium on laboratory shear testing of soils, ASTM STP 361, pp. 342-371. West Conshohocken, PA, USA: American Society for Testing and Materials.

Lefebvre, G. \& Poulin, C. (1979). A new method of sampling in sensitive clay. Can. Geotech. J. 16, No. 1, 226-233.

Lessard, G. \& Mitchell, J. K. (1985). The causes and effects of aging in quick clays. Can. Geotech. J. 22, No. 3, 335-346.

Lunne, T., Berre, T. \& Strandvik, S. (1997). Sample disturbance effects in soft low plastic Norwegian clay. In Proceedings of the symposium on recent developments in soil and pavement mechanics (ed. M. Almeida), pp. 81-102. Rio de Janeiro, Brazil, Rotterdam: Balkema.

Sandven, R. (1990). Strength and deformation properties of fine grained soils obtained from piezocone tests. $\mathrm{PhD}$ thesis, Norwegian Institute of Technology (now Norwegian University of Science and Technology), Trondheim, Norway.

Schjetne, K. (1971). The measurement of pore pressure during sampling. In Proceedings of the 4th Asian ISSMFE, special session on quality in soil sampling, Bangkok, pp. 12-16, Melbourne, Australia: International Group on Soil Sampling.

Skempton, A. W. \& Sowa, V. A. (1963). The behaviour of saturated clays during sampling and testing. Géotechnique 13, No. 4, 269-290, https://doi.org/10.1680/geot.1963.13.4.269.

Tanaka, H. (2008). Sampling and sample quality of soft clays. In Proc. of the geotechnical and geophysical site characterization (eds A. B. Huang and P. W. Mayne), pp. 139-157. London, UK: Taylor \& Francis 